\title{
ARE YOU WILLING TO PAY MORE FOR THE ARTS?
}

\author{
Martinette Kruger* \\ North-West University
}

Received: January 2016

\author{
Melville Saayman" \\ North-West University
}

Accepted: May 2016

\begin{abstract}
This study determines festival attendees' Willingness To Pay to support an increase, or prevent a decline, in arts performances and exhibitions. It uses the contingent valuation method to produce a profile of attendees, showing how much, if anything, they are willing to pay per month over and above their current taxes, and their reasons for being willing or unwilling to pay extra. Apart from Snowball (2005), no studies to date have examined Willingness To Pay to support the arts in a developing country like South Africa. This study of the Aardklop festival shows how Willingness To Pay for the arts appears to have changed in South Africa over the past decade and it appears that arts patrons are less willing to pay than a decade ago. It suggests strategies for sustaining the arts in South Africa and will help events managers to identify the attendees who are willing to pay more.
\end{abstract}

Keywords

Willingness To Pay (WTP), contingent valuation method (CVM), Heckman procedure, Aardklop, arts festival, South Africa

*Prof M Kruger is professor and researcher at TREદS (Tourism Research in Economic Environs and Society), North-West University, Potchefstroom, South Africa. [Martinette.Kruger@nwu.ac.za]

Prof M Saayman is Research Director at TREદS (Tourism Research in Economic Environs and Society), North-West University, Potchefstroom, South Africa. 


\section{INTRODUCTION}

Arts festivals are one of the fastest growing segments of events tourism. In South Africa they have considerable economic value, many being regarded as tourist attractions in themselves and thus valuable for destination development and marketing (Kruger, 2010; Kruger \& Saayman, 2012). Although of short duration, an event can have major economic benefits for the host city or region (Getz, 2008). It may also bring intangible benefits such as pleasure, image enhancement, national pride, and the building and expressing of community identity (Throsby, 2001; Kruger, 2010; Kruger \& Saayman, 2012).

However, in many countries the arts are coming under increasing financial pressure (Snowball \& Antrobus, 2001; Snowball \& Willis, 2006). This is particularly true of developing countries like South Africa, where the arts must compete with sectors such as housing, education and health for very limited public funds. A further problem in South Africa is that resources are still mostly apportioned along the lines of race and wealth. Many art patrons believe the government ought to provide financial support. However, while the South African government acknowledges the role of the arts in 'enhancing the country's identity and distinctiveness', encouraging 'nation building' and assisting in personal development by increasing self-confidence and promoting self-esteem (RSA, 1996), the primary focus of policy since 1994 has been on job creation and the financial benefits that the arts provide, rather than on their less tangible benefits (Snowball, 2005; Mzansi Golden Economy Strategy, 2011). As a result, the arts in South Africa are becoming increasingly dependent on private sponsors and loyalty clubs. The country's over 600 arts festivals are struggling to survive in an increasingly crowded marketplace (Kruger, 2010; Pretorius, Viviers \& Botha, 2014). Are festival visitors to South African festivals willing to pay to sustain the arts and, if so, how much? This is the question our study set out to answer.

For the purpose of our research we define an arts festival as 'a community themed event or celebration designed to showcase different art forms and activities - along with the related tourism and hospitality experiences - for external communities' (Kruger \& Petzer, 2008:113). Festivals have in common intense production, a condensed programme, and a cultural experience planned with a specific purpose (McKercher et al., 2006). We focus on Aardklop, one of South Africa's largest national arts festivals, held annually in the town of Potchefstroom in the NorthWest Province. This festival's aim is to preserve and enhance the Afrikaans language and culture. Aardklop (literally 'earth beat', or 'pulse of the earth') offers an array of genres: Afrikaans cabaret, classical music, jazz, musical theatre, drama, street theatre and children's theatre, dance, rock concerts, literature and the visual arts. The visitors, mainly Afrikaans, pay a daily entrance fee (reduced for Potchefstroom residents, children under 12 and pensioners) to enter the festival grounds for arts and crafts and open air music performances. Tickets for the theatre productions (at various venues across Potchefstroom, such as schools and the university) are bought separately and prices vary depending on the popularity of the production and the actors. An estimated 150000 people attend the festival over five days each 0 ctober.

This study determines these festival attendees' Willingness To Pay (WTP) to support an increase in arts performances and exhibitions or to prevent their decline. We assume that art festival attendees might be willing to support the arts and our analysis produces a profile of attendees, showing how much, if anything, they are willing to pay per month over and above their current taxes and their reasons for being willing or unwilling to pay extra. With the exception of Snowball's (2005) study, no other studies to date have investigated Willingness To Pay to support the arts in a developing country like South Africa. Our study is thus opportunely timed to show whether this 
WTP has changed over the past decade, and if so how and why. It therefore fills a gap in the current literature. It suggests strategies for sustaining the arts in South Africa and will help event managers to identify markets that are willing to pay more to sustain the arts. It appears from our results that people who are willing to pay more in taxes to support the arts share some demographic and behavioural characteristics with people whom previous studies have been found to be bigger spenders at arts festivals.

\section{LITERATURE REVIEW}

This section reviews the literature on Willingness To Pay for the arts and the application of the contingent valuation method (CVM) in the arts.

\subsection{Willingness to pay for the arts}

The WTP for a good is defined as 'the maximum amount a customer is willing to pay for the good' and can usually be estimated by analysing market information such as the price and the customers' purchasing behaviour (Park \& MacLachlan, 2008:691). WTP studies have been used extensively and with reasonably good success rates in the valuation of goods in cultural economies (Throsby, 1984; Noonan, 2003; Whitehead \& Finney, 2003). These studies use stated preference methods that elicit the value of non-market externalities by asking respondents what they would be willing to pay to bring about or avoid a certain scenario (Snowball, 2005). Responses are therefore contingent on the stated scenario.

Although many WTP studies have been conducted on cultural goods (Noonan, 2003), very few have looked specifically at cultural events like art festivals and even fewer have been conducted in developing countries. The economic value of artistic and cultural goods such as an arts festival can be estimated in several ways, such as travel cost, hedonic pricing and contingent valuation. The contingent valuation method (CVM) is the most commonly used method for determining WTP, despite criticism (mostly related to the hypothetical nature of the created market and the difficulty of placing a value on hard-to-define goods (Diamond \& Hausman, 1994; Epstein, 2003). Throsby and Withers (1979) and Frey and Pommerehne (1989), among others, discuss various arguments for public support of cultural activities. There is broad agreement that the main reason for such support is positive consumer externalities and that CVM is the most effective way to quantify these externalities (Noonan, 2004; Snowball, 2005).

Arts organisations receive their revenue from a variety of sources, such as ticket sales, concessions and advertising, and individual, corporate and government donations (Thompson, Berger, Blomquist \& Allen, 2002). As the arts therefore comprise a significant area of economic activity (Throsby, 1994), estimating their economic value is an important and growing field of applied research (Noonan, 2003). The value that individuals place on the arts has been a focus of recent research, particularly since government funding of the arts has received much scrutiny from lawmakers and citizens and has decreased over time, along with private donations to arts organisations. Local and regional organisations and governments are increasingly being asked to provide a larger share of funding to support arts organisations (Thompson et al., 2002; Johanson, Glow \& Kershaw, 2014; Lawley, 2015).

Most economists would agree that culture and the arts do not operate like normal goods in the market (Snowball \& Webb, 2008). One argument is that the arts have the characteristics of public goods (Throsby, 1994). This has implications for estimating the value of the arts, because price 
value, determined by the market, is often what is used as a measure of value (Snowball \& Webb, 2008). Thompson et al. (2002), however, argue that, by buying tickets and donating time and money, residents of a country can also demonstrate the value they place on cultural activities. As with environmental amenities, people may be motivated to make donations to the arts because of their use value, option value or existence value, or all three. 'Use value' is the value placed on arts events by people who attend them (on-site use) or enjoy them indirectly, for example by viewing them on television or reading reviews (off-site use). Most of these people naturally share with arts organisations some of the use value they derive from arts performances by buying tickets or making donations, which helps to ensure access to the arts amenity they consume (Clark \& Kahn, 1988). 'Option value' refers to people's appreciation of arts events because they wish to retain the option to attend them. 'Existence value' means they perceive cultural or other benefits from these events, even though they do not attend them. Donations may be needed to encourage local arts organisations to offer more high-quality performances or exhibits, or, in the case of small towns and communities, to help organisations to exist. Potential donors may be uncertain whether an arts festival is worth supporting. If they know how much people value the festival, then they will be better able to weigh up its intangible benefits and costs in comparison with other (non-arts) events they might support. Valuation of cultural programmes and assets such as arts festivals therefore offers a way for decision-makers to compare the intangible benefits (and costs) of various alternatives (Noonan, 2003).

Festivals have been described as a complex cultural phenomenon and not merely an accumulation of cultural manifestations exhibited therein but rather a cultural good in themselves, a cultural manifestation in their own right, and a cultural process in which culture is consumed, reproduced and created' (Herrero, Sanz, Bedate \& del Barrio, 2011:1). A festival's value may be approached from a variety of standpoints (Devesa, Herrero, Sanz \& Bedate, 2006). For the artists directly involved, it constitutes the production of a cultural good in itself, whereas for those attending it may provide a range of use values (aesthetic value, enjoyment, entertainment, cognitive value etc.) (Kruger, 2010), as well as existence value related to its symbolic repercussions (Throsby, 2003). For policy-makers, a cultural festival is framed as a public good which may have an economic impact as well as certain intangible effects in the medium term on the area where it is held (Herrero et al., 2006). Seen from this point of view, it is especially vital that arts festivals should continue in developing countries like South Africa, not only for their substantial economic benefits to the host regions but also for their broader role in the survival and growth of the arts (Pretorius et al., 2014; Kruger, 2010).

\subsection{Application of CVM to cultural goods and the arts}

The contingent valuation method (CVM) has been widely used by economists, mostly for estimating the value of non-market goods, and mostly focusing on environmental goods (e.g. Mitchell \& Carson, 1989; Kenkel, Berger \& Blomquist, 1994; 0'Conor \& Blomquist, 1997; Ready, Berger \& Blomquist, 1997; Blumenschein, Johannesson, Blomquist, Liljas \& O'Conor, 1998; Whitehead \& Hoban, 1999; Cummings \& Taylor, 1999; Ethier, Poe, Schulze \& Clark, 2000; Gregory, 2000; Carlsson \& Martinsson, 2001; Blumenschein, Johannesson, Yokoyama \& Freeman, 2001). The literature offers only a few examples of CVM being used to measure cultural goods (e.g. Martin, 1994; Throsby \& Withers, 1979; Morrison \& West, 1986a, b), and most of these studies use CVM on very broadly defined goods. This limited use of CVM in the literature of cultural economics is quite surprising, given that much of this literature deals with justifying public subsidy of the arts (Hansen, 1997). 
CVM applications to arts and cultural resources have typically fitted into at least one of four categories: admission fees studies, undertaken at cultural institutions or heritage sites; preservation studies, looking at Willingness To Pay to maintain or restore cultural icons; alternate funding studies, estimating Willingness To Pay more for a facility; and new project studies, estimating values for projects that affect or provide cultural resources (Noonan, 2004). Previous contingent valuation studies of the arts have mainly considered funding for particular institutions, such as theatres and museum councils. In earlier studies, Throsby and O'Shea (1980), Thompson, Throsby and Withers (1983), Morrison and West (1986a,b), Glass, Clifford, Harris, Woolsey and Krider (1999) and Snowball and Antrobus (2001) found that respondents were willing to pay more through taxes to support the arts, while Thompson et al. (2002) found that respondents were willing to pay more through donations. Thompson et al. (2002) furthermore found that consumer demand for arts performances mostly follows a predictable pattern. The likelihood of respondents agreeing to make the requested donation rises as the size of the donation decreases. The likelihood is also higher of their being willing to offer support to prevent a $50 \%$ decline in performances than to prevent a $25 \%$ decline in returns. The mean WTP rises with income, and arts patron households have a much higher WTP than all households. WTP rises with on-site use factors such as frequency of attendance and also for arts patrons' households with off-site use such as watching arts events on television or reading about the arts in newspapers and magazines.

Hansen's CVM study of the arts (1997) found that Danish citizens' aggregate WTP to support the Royal Danish Theatre exceeded the public subsidy for the theatre. The results showed that $38 \%$ of the sample were willing to accept higher taxes to support the arts while $55 \%$ were unwilling and $7 \%$ were unsure. Hansen (1997) also found positive WTP among citizens who had never attended the theatre, suggesting that the Royal Danish Theatre has option and existence values for Danish citizens. Martin (1994) found that the social value of a particular Quebec museum exceeded its public subsidy. Santagata and Signorello (2000) found that the aggregate willingness of Naples residents to pay to support a local public cultural network of churches, palaces and a museum exceeded the public subsidy for the network. Results from the research showed that $52 \%$ of the respondents were willing to pay extra. Clark and Kahn (1988) used a hedonic wage approach to estimate Willingness To Pay for museums, zoos, symphonies, dance troupes and theatres in 279 metropolitan areas. They found a positive WTP to support an increase in the quality of these institutions, or an increase in their quantity in any particular city. The average household's WTP to support one additional museum, zoo, symphony, dance troupe or theatre ranged from $\$ 1$ for an additional theatre to $\$ 37$ for an additional symphony and $\$ 68$ for an additional zoo.

In the only South African study to date, Snowball (2005) determined respondents' WTP for two arts festivals (the National Arts Festival in Grahamstown and the Klein Karoo National Arts Festival in Oudtshoorn). The results suggested that the probability of being willing to pay to support these festivals depended to some extent on household income. It also depended on variables such as free attendance at shows, opinions about the potential economic or financial benefits of the festival, opinions about educational value, future use value, pride and whether shows at the festivals were too critical of current 'ways of life', and on some demographic variables, such as race (African-origin visitors were willing to pay more for the main festival than European-origin visitors). In addition, the results showed that the benefits of these cultural events accrue not only to the wealthier, mainly Caucasian residents, but also to lower-income African people. These findings strongly suggest that governments of developing countries should sponsor and support the arts. If public funding for arts festivals is withdrawn, the losers will be not only the wealthy 
but also the poorer people, who rely on these festivals for both cultural stimulation and a little extra cash.

The results of the above studies collectively show that CVM, by revealing what people value, can offer policymakers for major arts organisations and cultural institutions guidance in allocating scarce resources. CVM studies can also help managers to improve pricing strategies and target fundraising efforts effectively.

\section{METHOD OF RESEARCH}

This study was conducted by means of a structured questionnaire. This section describes the questionnaire, the sampling and survey method, including the demographic and behavioural profile of the respondents, and the statistical analysis.

\subsection{The questionnaire}

The questionnaire was divided into four sections. Section A captured demographic details (gender, home language, age, occupation, home province) and spending behaviour (number of people paid for, length of stay, times attended and expenditure). Section B captured information specific to visitors' behaviour during the festival (preferred genres and main reason for attending). Section $C$ asked whether respondents were willing to pay to support the arts. The question was: 'Would you be willing to pay extra a month over and above your current taxes, if you knew the money was used to support the arts?' Respondents could answer 'yes', 'no' or 'do not know'. If the answer was 'yes', then in the follow-up question they were asked to indicate the amount they were willing to pay, and then to rate the importance of 11 statements about why they would be willing to pay extra. If the answer was 'no' or 'do not know', they were asked to rate 8 statements about why they would be unwilling. These responses were measured on a five-point Likert scale, where $1=$ totally disagree, 2 = disagree, $3=$ neutral, $4=$ agree and $5=$ totally agree . Section C was largely based on the work by Snowball (2005) as no similar studies to date have examined Willingness To Pay to support the arts in South Africa. Sections $C$ thus satisfied the criteria for content validity.

Since, the question 'Are you willing to pay extra?' had a 'Do not know' category (as similarly used by Snowball [2005]), if the respondent chose an amount in the follow-up question, 'How much are you willing to pay?' this was taken as indicating Willingness To Pay. However, respondents who did not complete the 'how much' question were considered to be unwilling to pay (i.e. a protest vote).

\subsection{Sampling and survey method}

In total, 400 questionnaires were distributed over a period of five days ( 7 to 110 ctober 2014) by means of simple random sampling and 391 were returned sufficiently completed to be included in the analysis. In a population of $100000(\mathrm{~N}), 398$ respondents (n) are seen as representative and result in a $95 \%$ level of confidence with a $\pm 5 \%$ sampling error (Krejcie \& Morgan, 1979). Since approximately 40000 visitors attended Aardklop in 2009 (Kruger, Saayman, Saayman \& Oberholzer, 2009:31), the number of completed questionnaires is greater than required. All questionnaires were completed at the main festival grounds and at various venues in Potchefstroom, where fieldworkers moved around to minimise bias. Adult visitors were randomly 
selected as they entered or left the grounds and when they were sitting down and relaxing at the various venues. The five fieldworkers were trained to ensure that they understood the aim of the study and the questionnaire and could brief respondents about the purpose of the research. Questionnaires were also handed out progressively towards the end of the festival to obtain a more detailed account of visitor spending. Each fieldworker had 80 questionnaires to distribute cumulatively over the five days of the festival: 10 on the first day, 15 on the next, then 17,18 and finally 20 .

Respondents at Aardklop were mostly Afrikaans-speaking (85\%), female (63\%), in their early thirties (average age of 31 ), students $(34 \%)$ or in a professional occupation (16\%) and either local residents from the North-West (29\%) or visitors from Gauteng (51\%). On average, they travelled in groups of four, were financially responsible for two people, spent over R2100, purchased two tickets for productions and shows, spent two days and two nights at the festival, attended mostly comedy (39\%), drama (35\%) and music theatre and cabaret (32\%) productions, and had attended the festival four times previously.

\subsection{Statistical analysis}

To determine who would be willing to pay to support the arts, the Heckman selection model was estimated using maximum likelihood with the software EViews. The Heckman model entails the simultaneous estimation of the selection and response equation, with the selection equation being a probit-type model and the response equation being a normal regression model with the natural log of the ZAR amount that respondents were willing to pay as the dependent variable. The covariates included in each were determined using separate selection and response equations prior to estimating the Heckman model. We wanted to know whether they were willing to pay an additional amount each month, how much they were willing to pay, and what were their reasons for being willing or unwilling to pay extra, i.e. the predictors of their WTP. The dependent variable in the present study is similar to that used in earlier studies by Throsby and O'Shea (1979), Thompson, Throsby and Glenn (1983), Morrison and West (1986a, b), Glass et al. (1999) and Snowball and Antrobus (2001), i.e. respondents' Willingness To Pay more through taxes to support the arts.

The Heckman procedure assumes that the decision to pay and the amount one is willing to pay occur simultaneously and it involves estimation in two steps, namely selection and response. The linear Heckman model therefore entails the estimation of the following two equations (IHS Global Inc., 2013):

$$
\begin{aligned}
& y_{i}=X_{i}^{\prime} \beta+\varepsilon_{i} \\
& z_{i}=W_{i} \gamma+u_{i}
\end{aligned}
$$

where $z_{i}$ is a binary variable and $y_{i}$ is only observed when $z_{i}=1$, in other words, when respondents say they are willing to pay. Equation (2) is the identification or selection equation and is a probittype equation, while equation (1) is the response equation, which shows the relationship between the predictors $\left(X_{i}\right)$ and the amount that respondents are willing to pay $\left(y_{i}\right)$. The error terms, $\varepsilon_{i}$ and $u_{i}$, follow a bivariate normal distribution with $\rho$ as the correlation coefficient and $\sigma$ as the scale parameter: 


$$
\left[\begin{array}{l}
\varepsilon_{i} \\
u_{i}
\end{array}\right] \sim N\left[\begin{array}{cc}
\sigma^{2} & \rho \sigma \\
\rho \sigma & 1
\end{array}\right]
$$

The Heckman model is estimated using full information maximum likelihood instead of the twostep procedure (limited information maximum likelihood), since Puhani (2000) says it gives more robust estimation results because it controls for collinearity. We follow the process suggested by Strazzera, Genius, Scarpa, and Hutchinson (2003) and first estimate the two processes separately in order to identify the most suitable covariates before estimating the Heckman model.

For the selection equation (equation (2)), the dichotomous variable takes the value of 1 if the respondent indicated Willingness To Pay. Since the dependent variable is dichotomous, logit regression analysis was used to identify the significant covariates. The logistic regression analyses were done using both SPSS and EViews software (the latter used for the LMAX model). The logit model takes the natural log of the odds ratio, i.e. $L_{i}=\ln \left(\frac{P_{i}}{1-P_{i}}\right)$, and uses this in a linear regression model (where $P_{i}$ is the probability that WTP takes the value of 1 ). The logit model therefore takes the following specification (Asteriou \& Hall, 2011):

$$
L_{i}=\beta_{1}+\beta_{2} X_{2 i}+\beta_{3} X_{3 i}+\cdots+\beta_{k} X_{k i}+\varepsilon_{i}
$$

Interpretation of the estimated $\beta$ coefficients is problematic, since it shows the change in $P_{i}$ for a unit change in $X_{i}$. The odds ratio is therefore often interpreted (Asteriou \& Hall, 2011).

In identifying the covariates for the selection and response equation, we used a stepwise procedure (both stepwise forward and stepwise backward). SPSS offers a stepwise procedure for logistic regression models (i.e. the selection equation) and EViews for mean regression models (i.e. the response equation). In both cases the model starts only with an intercept and adds additional variables to the model based on the score statistic (Field, 2009), with a cut-off criterion of 0.5 . The variables included in the Heckman model were the following:

- $A G E$ - the age of the respondent.

- FEMALE - a dichotomous variable that takes the value of 1 if the respondent is female and 0 if the respondent is male.

- AFR - a dichotomous variable that takes the value of 1 if the respondent is Afrikaansspeaking, 0 otherwise.

- OCCU - The 12 occupation categories that were included were ranked into three categories, from low-earning (OCCU1) to high-earning (OCCU3).

- INCOME: Since income is a sensitive topic, respondents could pick one of seven income categories based on the South African life standard measurement (LSM). The variables were INCOMEI = below ZAR20 000 per year, INCOME 2 = ZAR20 000-140 000; INCOME3 = ZAR140 001221000 , INCOME4 = ZAR221001-305000, INCOME5 = ZAR305 001-431000, INCOME6 = ZAR431 100-552 000, INCOME7 = above ZAR552 001. The majority of respondents fell under INCOMEI (33\%), INCOME2 (20\%), and INCOME3 (15\%).

- DAYS - the number of days spent at the festival.

- NWP - a dichotomous variable that takes the value of 1 if the respondent is from the NorthWest Province, 0 otherwise.

- GAUTENG - a dichotomous variable that takes the value of 1 if the respondent is from Gauteng, 0 otherwise.

- GROUP - the size of the travel party. 
- PAID - the number of people a respondent was financially responsible for during the festival.

- SPEND - indicates the total spending by the respondent during the festival and can be used as a proxy for income (i.e. means to pay) in natural logs.

- YATTEND - the number of times a respondent had previously attended the festival.

- REASON - a dichotomous variable that takes the value of 1 if respondents said the festival was their main reason for visiting Potchefstroom, 0 otherwise.

- SHOWS - dichotomous variables that take the value of 1 if respondents said they had attended a particular type of show (drama, word art and poetry, children's' theatre, theatre discussions, music theatre and cabaret, choir and ensemble, rock, visual arts and exhibitions and comedy), and 0 if the answer was no.

The dependent variable for the selection equation (WTP) is coded as a dichotomous variable, taking the value of $l$ if respondents said they were willing to pay extra per month over and above their current taxes to support the arts. In the response equation, the dependent variable is the natural log of the maximum amount they said they were willing to pay to support the arts (LMAX).

\section{RESULTS}

The results of the final Heckman estimation are shown in TABLE 1. Respondents who said they were willing to pay extra to support the arts through taxes (139 respondents or $36 \%$ ) responded with an average maximum amount of R220.86 while $29 \%$ ( 113 respondents) were unwilling and $26 \%$ (101 respondents) were uncertain. The percentage of respondents in the present study correlates with the $38 \%$ of willing Danish respondents in Hansen's (1997) study; however it is a much lower percentage than the $52 \%$ willing Italian respondents in Santagata and Signorello's (2000) study.

TABLE 1: Results of the Heckman model

\begin{tabular}{|c|c|c|c|c|}
\hline Variable & Coefficient & Std. error & t-statistic & Prob. \\
\hline \multicolumn{5}{|c|}{ Response equation - LMAX } \\
\hline C & 4.274359 & 0.437900 & 9.761046 & 0.0000 \\
\hline REASON & 0.874979 & 0.283532 & 3.086001 & 0.0023 \\
\hline THEATRE & 1.584756 & 0.637606 & 2.485479 & 0.0137 \\
\hline CLASSICAL & -1.366212 & 0.648179 & -2.107768 & 0.0362 \\
\hline NWP & 0.474651 & 0.325478 & 1.458323 & 0.1462 \\
\hline \multicolumn{5}{|c|}{ Selection equation - WTP } \\
\hline C & -1.144381 & 0.251267 & -4.554445 & 0.0000 \\
\hline$A G \varepsilon$ & 0.016435 & 0.006916 & 2.376157 & 0.0184 \\
\hline TICKETS & 0.081206 & 0.035099 & 2.313657 & 0.0216 \\
\hline FEMALE & -0.551097 & 0.198675 & -2.773857 & 0.0060 \\
\hline \multicolumn{5}{|c|}{ Interaction terms } \\
\hline
\end{tabular}




\begin{tabular}{lcccc}
\hline @LOG(SIGMA) & -0.073201 & 0.130868 & -0.559354 & 0.5765 \\
\hline @ATAN(RH0)*2/PI & -0.777367 & 0.689596 & -1.127279 & 0.2609 \\
\hline SIGMA & 0.929414 & 0.121630 & 7.641296 & 0.0000 \\
RHO & -0.420670 & 0.273646 & -1.537277 & 0.1257 \\
\hline & & & 1.059966 \\
Mean dependent var. & 4.490152 & S.D. dependent var. & 1.633325 \\
S.E. of regression & 0.485907 & Akaike info. criterion & 1.800335 \\
Sum squared resid. & 50.52669 & Schwarz criterion & 1.700731 \\
\hline Log likelihood & -172.7491 & Hannan-Puinn crit. & \\
\hline
\end{tabular}

Source: Authors' analysis

The response equation indicated that the amount a respondent was willing to pay was positively associated with 'festival being the main reason for travelling to Potchefstroom' and 'attending theatre discussions'. The variable 'classical music productions' was negatively related to WTP, indicating that respondents who purchased tickets for this type of production were not willing to pay more to support the arts. Kruger et al. (2009) and Botha, Slabbert, Rossouw and Viviers (2011) also found a positive correlation between 'Aardklop is main reason for travelling to Potchefstroom' and higher spending, and Kruger, Saayman and Ellis (2010) similarly found an inverse relationship between classical music productions and higher spending. The results, however, contradict the finding by Kruger et al. (2009), Botha et al. (2011) and Kruger, Saayman and Saayman (2012) that visitors interested especially in drama, music theatre, cabaret and contemporary music tended to be high spenders at the Klein Karoo National Arts Festival (the biggest Afrikaans festival in South Africa). The results also contradict Saayman et al.'s (2009) finding that visitors who attended more dance shows spent more at the Grahamstown National Arts Festival (the oldest English arts festival in South Africa). However, the relationship between the type of show and visitors' WTP is not clear. While 'North-West Province as place of origin' was also identified by the stepwise procedure, it was not significant in the final estimated response equation. The sign of the coefficient indicated that visitors travelling from this province were willing to pay more to support the arts. Although not previously identified as a variable that influences visitors' WTP, province of origin has been strongly linked to higher spending at arts festivals in South Africa. Kruger et al. (2009), Botha et al. (2011) and Kruger et al. (2012) found that festival visitors travelling from Gauteng tended to be higher spenders. It was therefore interesting to find that North-West Province had a positive relationship with WTP, since visitors from this province were associated with lower spending in those three studies. This could be because Aardklop is hosted in this province and these visitors are loyal to their local festival and want to see it continue.

From the selection equation (i.e. those who are willing to pay) it was evident that more demographic variables were predictors of WTP than behavioural variables. Age was positively related to WTP, indicating that older people were willing to pay more to support the arts. This result is consistent with findings by Kruger $(2009,2010)$, Kruger et al. (2009), Saayman and Saayman (2009), Botha et al. (2011) and Kruger et al. (2012), all of whom found a positive correlation between older age and higher spending at national arts festivals. Respondents who purchased more tickets for shows and productions at the festival were also willing to pay more. This finding is also consistent with Kruger et al.'s (2012) research in which higher spending at the Klein Karoo National Arts Festival was associated with more tickets purchased for shows and productions. In 
the present study, fewer female than male respondents were willing to pay more to support the arts. This result differs from Snowball's (2005) finding that there were no significant differences between male and female respondents as regards WTP to support the arts. Also different to Snowball's (2005) findings, income was not found to be a significant predictor of WTP in the present study.

TABLE 2 shows the descriptive results of asking respondents the reasons for their Willingness or un-Willingness To Pay more to support the arts. Based on the mean values, the main reasons for being willing were: Supporting the arts leads to community pride (3.99), Arts festivals, theatres and exhibitions promote arts and culture (3.98) and Supporting the arts ensures the future and preservation of culture (3.96). These reasons differ from Snowball's 2005 findings: in her study of the Grahamstown National Arts Festival in 2003, most respondents picked 'job creation' and 'employment opportunities' and 'entertainment value of the festival' as their main reasons for being willing to support the arts. In her 2000 study, respondents picked 'community education', 'exposing people to culture' and 'nation building' as their main reasons for supporting the festival. These reasons were, however, directly linked to supporting the continuation of the festival and not the arts in general. The primary reasons given in the present study for not being willing to support the arts were: Increase in living expenses (3.55), I believe that it is the government's role to support the arts (3.26) and I already pay too much tax, I do not want to pay more (3.12). These reasons also differ from Snowball's (2005) finding that respondents cited the deterioration in the quality or organisation of the Grahamstown National Arts Festival and the lack of economic benefits accruing from it as their main reasons for not being willing to pay to support it. Our findings, however, support the results obtained for the Klein Karoo National Arts Festival, where respondents cited income constraints as their main reason for being unwilling to support the arts.

TABLE 2: Descriptive results: reasons for being willing or unwilling to pay more to support the arts $(N=391)$

\begin{tabular}{|c|c|c|c|c|c|}
\hline & $N^{*}$ & Min. & Max. & Mean & Std. dev. \\
\hline \multicolumn{6}{|l|}{ Reasons willing to pay more } \\
\hline Supporting arts leads to community pride & 264 & 1 & 5 & 3.99 & .949 \\
\hline $\begin{array}{l}\text { Festivals, theatres and exhibitions promote arts } \\
\text { and culture }\end{array}$ & 264 & 1 & 5 & 3.98 & .896 \\
\hline $\begin{array}{l}\text { Supporting arts ensures future and preservation of } \\
\text { culture }\end{array}$ & 269 & 1 & 5 & 3.96 & 1.018 \\
\hline Supporting arts makes educational contribution & 266 & 1 & 5 & 3.94 & .923 \\
\hline Festivals, theatres and exhibitions attract tourists & 261 & 1 & 5 & 3.92 & .958 \\
\hline Support makes arts accessible to broader society & 268 & 1 & 5 & 3.88 & .893 \\
\hline $\begin{array}{l}\text { Supporting arts important since government } \\
\text { cannot fulfil needs of all cultural groups }\end{array}$ & 266 & 1 & 5 & 3.85 & 1.012 \\
\hline Support ensures future of arts & 264 & 1 & 5 & 3.84 & .957 \\
\hline Supporting arts can lead to job opportunities & 262 & 1 & 5 & 3.82 & .939 \\
\hline $\begin{array}{l}\text { Arts have economic value for host communities and } \\
\text { country }\end{array}$ & 269 & 1 & 5 & 3.80 & .953 \\
\hline
\end{tabular}




\begin{tabular}{|c|c|c|c|c|c|}
\hline & $N^{*}$ & Min. & Max. & Mean & Std. dev. \\
\hline Country is poor if it does not support arts & \multirow[t]{2}{*}{261} & \multirow[t]{2}{*}{1} & \multirow[t]{2}{*}{5} & \multirow[t]{2}{*}{3.76} & \multirow[t]{2}{*}{1.063} \\
\hline Reasons not willing to pay more & & & & & \\
\hline Increase in living expenses & 254 & 1 & 5 & 3.55 & 1.194 \\
\hline It is government's role to support arts & 263 & 1 & 5 & 3.26 & 1.234 \\
\hline Already pay too much tax, do not want to pay more & 258 & 1 & 5 & 3.12 & 1.238 \\
\hline Have more important things to spend money on & 263 & 1 & 5 & 3.05 & 1.177 \\
\hline Arts do not provide enough job opportunities & 262 & 1 & 5 & 2.94 & 1.269 \\
\hline $\begin{array}{l}\text { Only those who regard arts important should } \\
\text { support }\end{array}$ & 257 & 1 & 5 & 2.71 & 1.174 \\
\hline $\begin{array}{l}\text { Unimportant if there are fewer festivals, theatres or } \\
\text { exhibitions }\end{array}$ & 259 & 1 & 5 & 2.66 & 1.220 \\
\hline Only the rich benefit from arts & 261 & 1 & 5 & 2.56 & 1.238 \\
\hline
\end{tabular}

Source: Authors' analysis

*Some respondents gave reasons both for and against, regardless of whether they said they were willing to pay, unwilling or unsure. All the responses are counted in the table.

\section{CONCLUSIONS AND RECOMMENDATIONS}

This study sought to provide answers to two questions: 'Are festival visitors, specifically those attending the Aardklop festival, willing to pay extra to support the arts?' and 'If so, how much?' In answer to the first question, the study found that a large percentage $(29 \%)$ of the respondents were not willing to pay while $26 \%$ were uncertain. Only a small percentage ( $36 \%$, about a third) of the respondents were willing. In answer to second question, the average maximum amount respondents were willing to pay was 220.86 ZAR (approximately 18 USD). Our study differed somewhat from Snowball's (2005): she focused on supporting the continuation of a particular arts festival in South Africa whereas we focused on supporting the arts in general, and she asked about respondents' Willingness To Pay an additional amount from their monthly income, whereas we asked about Willingness To Pay extra taxes. These differences may explain some of the differences in our findings.

Using contingent valuation, our study identified some important demographic and behavioural predictors of the amount respondents were willing to pay to support the arts. The identified predictors both support and contradict previous research on the topic and more parallels were found when the results were compared with studies of predictors of higher spending rather than WTP studies. Our findings for those who were willing to support the arts differed significantly from the findings for those who were not. Those who were willing to support the arts through additional taxes were influenced more by external factors, such as the valuable role the arts play in community pride and the enhancement of culture, than by internal factors Those who were not willing to pay were influenced more by internal factors such as an increase in their living expenses, which made it difficult for them to afford the luxury of attending a festival, let alone helping to support it financially.

We found that more demographic than behavioural variables influenced WTP. The demographic variables influencing WTP were as follows. Age had a positive correlation with WTP, corroborating 
findings by Kruger $(2009,2010)$, Kruger et al. (2009), Saayman and Saayman (2009), Botha et al. (2011) and Kruger et al. (2012); however, those studies were of the determinants of higher spending at arts festivals, not WTP. This result is, however, not surprising since higher income is associated with older age and increased exposure to the arts usually intensifies the desire to support and preserve the arts. While previous studies (see Snowball, 2005) were inconclusive about the correlation between gender and WTP, our study found that women were less willing to pay than men. We also found that place of origin had a positive association with WTP, in the case of province of origin (North-West Province), which was also not evident in previous studies. This result, however, contradicts findings about the predictors of higher spending at national arts festivals by Kruger et al. (2009), Botha et al. (2011) and Kruger et al. (2012), where Gauteng was found to be a positive predictor of higher spending. Possible reasons for the result for North-West Province may be that, since Aardklop is hosted in the province, these visitors may value the continuation of the arts as represented by their local festival, and not having large travel expenses may make them more willing to offer financial support.

The following were our findings for behavioural variables. Respondents who purchased more tickets for shows and productions at the festival were willing to pay more to support the arts, supporting the findings by Kruger et al. (2012) that higher ticket purchases may be associated with higher income. There was a positive correlation between 'festival as main reason for travelling to Potchefstroom' and WTP. Festival organisers should encourage and endeavour to expand this market as they are true 'festinos' - visitors who are dedicated to the festival as well as to the continuation of the arts. 'Attending theatre discussions' was positively correlated with WTP but 'classical music productions' was negatively correlated with WTP, supporting the findings by Kruger et al. (2010), but contradicting the findings obtained in the determinants of higher spending studies by Kruger et al. (2012), Saayman et al. (2009) and Kruger (2009). The results however imply that festival organisers should re-think the pricing strategies of these productions as well as the number and quality of the different genres in the programme. This is especially important given the increase in the number of arts festivals in South Africa and the resulting competition for visitors and funding.

When it came to reasons for being willing or unwilling to pay to support the arts, the main reasons we found were: Supporting the arts leads to community pride, Arts festivals, theatres and exhibitions promote the arts and Supporting the arts ensures the future and preservation of culture. This differs from Snowball's (2005) findings, where the reasons were directly linked to supporting the continuation of the festival and not the arts in general. The main reasons for not being willing to support the arts were: Increase in living expenses, / believe that it is the government's role to support the arts and I already pay too much tax, I do not want to pay more. These reasons also differ from Snowball's (2005) findings from the Grahamstown National Arts Festival but support those for the Klein Karoo National Arts Festival which, like Aardklop, is an Afrikaans festival. This suggests that the type of festival and its character and also the characteristics of the festival visitor may influence the WTP.

Comparing the results of the present study with Snowball's (2005) findings a decade earlier, we may surmise that the economic climate in the country are affecting people's willingness to support the arts, especially through taxes. For this reason, it might be more viable to establish an arts council or fund or a private sector initiative or board that citizens can support through donations or monthly subscriptions, rather than asking them to support the arts through additional taxes. It is therefore advised that the private sector explore other models to expand and support the arts in the country. In addition, an investigation should be launched to identify priority areas and the arts that are struggling, to help design a framework or strategy that can 
address these issues. Further research should also determine respondents' roles and contribution to the arts in general, and find out what art forms they support (festivals, productions, art exhibitions, theatre, etc.) and how much they spend annually to support them.

\section{Acknowledgement}

The authors' gratefully acknowledge financial assistance from the NRF (National Research Foundation). We furthermore extend our gratitude towards Prof Andrea Saayman for her help and guidance regarding the statistical analyses. Finally, we are grateful to the research team, fieldworkers, and respondents who were willing to form part of the survey.

\section{LIST OF REFERENCES}

Asteriou, D. \& Hall, S. G. (2011). Applied Econometrics. New York: Palgrave Macmillan.

Blumenschein, K., Johannesson, M., Blomquist, G. C., Liljas, B. \& O'Conor, R.M. (1998). Experimental results on expressed certainty and hypothetical bias in contingent valuation. Southern Economic Journal, 65(1), pp. 169-177.

Blumenschein, K., Johannesson, M., Yokoyama, K. \& Freeman, P. (2001). Hypothetical versus real Willingness To Pay in the health care sector: results from a field experiment. Journal of Health Economics, 20(3), pp. 441-457.

Botha, K., Slabbert, E., Rossouw, R., \& Viviers, P. A. (2011). Expenditure-based segmentation of visitors to Aardklop National Arts Festival. South African Theatre Journal, 25(2), pp. 142-166.

Carlsson, F. \& Martinsson, P. (2001). Do hypothetical and actual marginal Willingness To Pay differ in choice experiments? Application to the valuation of the environment. Journal of Environmental Economics and Management, 41(2), pp. 179-192.

Clark, D.E. \& Kahn, J. R. (1988). The social benefits of urban cultural amenities. Journal of Regional Science, 28(3), pp. 363-377.

Cummings, R.G. \& Taylor, L.0. (1999). Unbiased value estimates for environmental goods: a cheap talk design for the contingent valuation method. American Economic Review, 89(3), pp. 649-665.

Devesa, M., Herrero, L. C., Sanz, J. A., \& Bedate, A. (2006, July). Economic analysis of a festival demand. The case of the Valladolid International Film Festival. In Proceedings of the $14^{\text {th }}$ International Conference of the ACEI, 6-9 July, Vienna, Austria.

Diamond, P.A. \& Hausman, J.A. (1994). Contingent valuation: is some number better than no number? Journal of Economic Perspectives, 8(4), pp. 45-64.

Epstein, R.A. (2003). The regrettable necessity of contingent valuation. Journal of Cultural Economics, 27(3-4), pp. 259-274.

Ethier, R.G., Poe, G.L., Schulze, W.D. \& Clark, J. (2000). A comparison of hypothetical phone and mail contingent valuation responses for green-pricing electricity programs. Land Economics, 76(1), pp. $54-67$.

Field, A. (2009). Discovering Statistics using SPSS, $3^{\text {td }}$ edition. London: SAGE.

Frey, B.S. \& Pommerehne, W.W. (1989). Art investment: an empirical inquiry. Southern Economic Journal, 56(2), pp. 396-409. 
Getz, D. (2008). Event tourism: definition, evolution, and research. Tourism Management, 29(3), pp. 403-428.

Glass, R.H., Clifford, N., Harris, B., Woolsey, C. \& Krider, C.E. (1999). Economic Scope, Impact and Marketing Study of the Kansas Arts Commission. Kansas: University of Kansas, Institute for Public Policy and Business Research Report.

Gregory, R.S. (2000). Valuing environmental policy options: a case study comparison of multiattribute and contingent valuation survey methods. Land Economics, 76(2), pp. 151-173.

Hansen, T.B. (1997). The willingness-to-pay for the Royal Theatre in Copenhagen as a public good. Journal of Cultural Economics, 21(1), pp. 1-28.

Herrero, L.C., Sanz, Á. \& Devesa, M. (2011). Measuring the economic value and social viability of a cultural festival as a tourism prototype. Tourism Economics, 17(3), pp. 639-653.

Herrero, L. C., Sanz, J. Á., Devesa, M., Bedate, A., \& Del Barrio, M. J. (2006). The Economic Impact of Cultural Events A Case-Study of Salamanca 2002, European Capital of Culture. European Urban and Regional Studies, 13(1), pp. 41-57.

IHS Global Inc. (2013), EViews 8 User's Guide II. Irvin, CA: IHS Global Inc.

Kenkel, D., Berger, M. \& Blomquist, G. (1994). Contingent valuation of health. In G. Tolley, \& D. Kenkel (eds.) Valuing Health for Policy: An Economic Approach. Chicago: University of Chicago Press (pp. 72 104).

Krejcie, R.V. \& Morgan, D.W. (1970). Determining the sample size for research activities. Educationa/ and Psychological Measurement, 30(3), pp. 607-610.

Kruger, M. (2009). Spending behaviour of visitors to the Klein Karoo National Arts Festival. Unpublished Masters Dissertation, North-West University, Potchefstroom.

Kruger, M. (2010). A critical evaluation of market segmentation at national arts festivals in South Africa. Unpublished PhD thesis, North West University, Potchefstroom.

Kruger, M. \& Saayman, M. (2012). When do festinos decide to attend an arts festival? An analysis of Innibos Arts Festival. Journal of Travel and Tourism Marketing, 29(2), pp.147-162.

Kruger, M., Saayman, M., \& Ellis, S. M. (2010). Determinants of visitor expenditure at the Aardklop National Arts Festival. Event Management, 14(2), pp. 137-148.

Kruger, M., Saayman, M., \& Saayman, A. (2012). Identifying the 'big spenders' at a national arts festival. Acta Academica, 44(3), pp. 74-94.

Kruger, M., Saayman, M., Saayman, A. \& Oberholzer, S. (2009). Die profiel en ekonomiese impak van Aardklop Nasionale Kustefees. Unpublished research report. Potchefstroom: North-West University, Institute for Tourism and Leisure Studies.

Kruger, S. \& Petzer, D. (2008). Measuring tourists' satisfaction with quality of life issues at an arts festival. Acta Commercii, 8(1), pp. 113-127.

Martin, F. (1994). Determining the size of museum subsidies. Journal of Cultural Economics, 18(4), pp. 255-270.

McKercher, B., Mei, W.S. \& Tse, T.S. (2006). Are short duration cultural festivals tourist attractions? Journal of Sustainable Tourism, 14(1), pp. 55-66.

Mitchell, R.C. \& Carson, R.T. (1989). Using Surveys to Value Public Goods: The Contingent Valuation Method. Washington, DC: Resources for the Future. 
Morrison, W.G. \& West, E.G. (1986a). Child exposure to the performing arts: the implications for adult demand. Journal of Cultural Economics, 10(1), pp. 17-24.

Morrison, W.G. \& West, E.G. (1986b). Subsidies for the performing arts: evidence on voter preference. Journal of Behavioral Economics, 15(3), pp. 57-72.

Mzansi Golden Economy Strategy. (2011). Mzansi's Golden Economy Contribution of the Arts, Culture and Heritage Sector to the New Growth Path. Available:

http://www.gov.za/sites/www.gov.za/files/mzansi\%20golden\%20economy\%2020110411_2.pdf (Accessed 7 September 2015).

Noonan, D. (2003). Contingent valuation and cultural resources: a meta-analytic review of the literature. Journal of Cultural Economics, 27(3-4), pp. 159-176.

Noonan, D.S. (2004). Valuing arts and culture: a research agenda for contingent valuation. Journal of Arts Management, Law, and Society, 34(3), pp. 205-221.

0'Conor, R.M. \& Blomquist, G.C. (1997). Measurement of consumer-patient preferences using a hybrid contingent valuation method. Journal of Health Economics, 16(6), pp. 667-683.

Park, J.H. \& MacLachlan, D.L. (2008). Estimating Willingness To Pay with exaggeration bias-corrected contingent valuation method. Marketing Science, 27(4), pp. 691-698.

Pretorius, S.C., Viviers, P. \& Botha, K. (2014). Is it still about the arts? The perceived contribution of KKNK to the arts. South African Theatre Journal, 27(3), pp. 159-182.

Puhani, P. (2000). The Heckman correction for sample selection and its critique. Journal of Economic Surveys, 14(1), pp. 53-68.

Ready, R.C., Berger, M.C. \& Blomquist, G.C. (1997). Measuring amenity benefits from farmland: hedonic pricing vs. contingent valuation. Growth and Change, 28(4), pp. 438-458.

RSA (Republic of South Africa). (1996). White Paper on arts, culture and heritage. Department of Arts, Culture, Science and Technology, South Africa. Available:

http://www.polity.org.za/govdocs/whitepapers/arts.html (Accessed 13 August 2015).

Saayman, M. \& Saayman, A. (2014). Who is willing to pay to see the Big 7? Tourism Economics, 20(6), pp. 1181-1198.

Santagata, W. \& Signorello, G. (2000). Contingent valuation of a cultural public good and policy design: the case of 'Napoli Musei Aperti'. Journal of Cultural Economics, 24(3), pp. 181-204.

Snowball, J.D. (2005). Art for the masses? Justification for public support of the arts in developing countries - two arts festivals in South Africa. Journal of Cultural Economics, 29(1), pp. 107-125.

Snowball, J.D. \& Antrobus, G.G. (2001). Measuring the value of the arts to society: the importance of the value of externalities for lower income and education groups in South Africa. South African Journal of Economics, 69(4), pp. 752-766.

Snowball, J.D. \& Webb, A.C.M. (2008). Breaking into the conversation: cultural value and the role of the South African National Arts Festival from apartheid to democracy. International Journal of Cultural Policy, 14(2), pp. 149-164.

Snowball, J.D. \& Willis, K.G. (2006). Estimating the marginal utility of different sections of an arts festival: the case of visitors to the South African National Arts Festival. Leisure Studies, 25(1), pp. $43-56$. 
Strazzera, E., Genius, M., Scarpa, R. \& Hutchinson, G. (2003). The effect of protest votes on the estimates of WTP for use values of recreational sites. Environmental and Resource Economics, 25(4), pp. 461-476.

Thompson, B.J., Throsby, C.D. \& Withers, G.A. (1983). Measuring community benefits from the arts. Sydney: Macquarie University, School of Economic and Financial Studies.

Thompson, E., Berger, M., Blomquist, G., \& Allen, S. (2002). Valuing the arts: a contingent valuation approach. Journal of Cultural Economics, 26(2), pp. 87-113.

Throsby, D. (1984). The measurement of Willingness To Pay for mixed goods. Oxford Bulletin of Economics and Statistics, 46(4), pp. 279-289.

Throsby, D. (1994). The production and consumption of the arts: a view of cultural economics. Journal of Economic Literature, 32(3), pp. 1-28.

Throsby, D. (2001). Economics and Culture. Cambridge: Cambridge University Press.

Throsby, D. (2003). Determining the value of cultural goods: how much (or how little) does contingent valuation tell us? Journal of Cultural Economics, 27(3-4), pp. 275-285.

Throsby, C. D., \& Withers, G. A. (1979). The Economics of Performing Arts. New York: St. Martin's Press.

Throsby, C.D. \& O'Shea, M. (1980). The regional economic impact of the Mildura Arts Centre. Sydney: Macquarie University, School of Economic and Financial Studies.

Whitehead, J. \& Finney, S. (2003). Willingness To Pay for submerged maritime cultural resources. Journal of Cultural Economics, 27(3-4), pp. 31-240.

Whitehead, J.C. \& Hoban, T.J. (1999). Testing for temporal reliability in contingent valuation with time for changes in factors affecting demand. Land Economics, 75(3), pp. 453-465. 